\title{
Fabricação e caracterização de compósitos a base de cimento com incorporação de poliestireno expandido (isopor)
}

\section{(Fabrication and characterization of cement based composite materials with styrofoam inclusions)}

\author{
K. Strecker, C. A. Silva, T. H. Panzera \\ Departamento de Engenharia Mecânica - DEMEC, Universidade Federal de S. João Del-Rei - UFSJ, Praça \\ Frei Orlando 170, Centro, S. João Del-Rei, MG 36307-352 \\ strecker@ufsj.edu.br,carlosbasque@hotmail.com,tuliopanzera@hotmail.com
}

\begin{abstract}
Resumo
Há uma grande necessidade de materiais leves e resistentes na construção civil moderna. Materiais de baixo peso são usados como agregados em concretos, argamassas e pastas cimentícias, sendo assim o isopor é um tipo de agregado que pode ser utilizado para tal finalidade. Neste trabalho foi estudada a influência da quantidade de areia fina em 5,10 e $20 \%$ e também da quantidade de isopor em 20, 40 e 60\%, nas propriedades: densidade volumétrica, densidade aparente, porosidade aparente, resistência à compressão e módulo de elasticidade. Os materiais compósitos exibiram densidades variando entre 1250 e $1600 \mathrm{~kg} / \mathrm{m}^{3}$ e resistência de 9 a $18 \mathrm{MPa}$, para 60 e $20 \%$ de isopor, respectivamente. O aumento da fração de areia de 5 para $20 \%$ promoveu o aumento da densidade aparente e módulo de elasticidade dos compósitos. O efeito da adição de areia sobre a porosidade aparente e resistência mecânica exibiu variação, indicando o fator de empacotamento das partículas como principal responsável por tal comportamento. Os compósitos investigados exibiram uma distribuição de partículas de isopor homogênea, permitindo o uso das mesmas para fins não-estruturais. Palavras-chave: compósitos particulados, cimento, isopor.
\end{abstract}

\begin{abstract}
In civil engineering, an increasing demand for lightweight concretes exists, because a lower density results in significant benefits for structural elements. Polystyrene foams may be used in the fabrication of lightweight concretes with a large density range. In this work, the influence of fine grained sand $(<1 \mathrm{~mm})$ additions of 5,10 and $20 \%$ on the properties of a composite of cement with styrofoam additions of 20, 40 and 60\% has been studied. The composites were characterized by their density, porosity and compressive strength after 28 days. The density of the composites varied between 1250 and $1600 \mathrm{~kg} / \mathrm{m}^{3}$ with a strength of 18 and 9 MPa for additions of 20 and $60 \%$ styrofoam, respectively. The increase of the fraction of sand from 5 to $20 \%$ promoted the increase in bulk density and modulus of the composites. The effect of the addition of sand on the porosity and mechanical strength exhibited variation indicating the packing factor of the particles as the main responsible for this behavior. The composites investigated exhibited a uniform distribution of the polystyrene spheres, allowing their use for non-structural purposes.
\end{abstract}

Keywords: composite particulate, cement, styrofoam.

\section{INTRODUÇÃO}

Há uma grande necessidade de materiais leves e resistentes na construção civil moderna; o concreto leve é um deles, com alta resistência especifica, ou seja, alta relação resistência/densidade, podendo ser usado em diversos elementos estruturais.

Materiais de baixo peso específico podem ser usados como agregados nesse tipo de concreto, sendo classificados em dois tipos, naturais (púmice, farinha fóssil, escórias de carvão vulcânicas, etc.) e artificiais (perlita, xisto expandido, barro, ardósia, PFA sinterizado, etc.). O poliestireno expandido (EPS) é um tipo de agregado artificial de ultrabaixo peso (densidade inferior a $300 \mathrm{~kg} / \mathrm{m}^{3}$ ) $[1,2]$. Devido a sua baixa densidade, pode ser utilizado na fabricação de concretos de baixa densidade para aplicação na construção civil, tais como revestimento de painel, muro cortina, piso e blocos de concreto [3, 4]. Esse material pode ser também utilizado em aplicações mais específicas como, por exemplo, base de pavimentos, leito de vias férreas, material de construção para estruturas flutuantes ou barreiras no mar e material que absorve energia na proteção de instalações militares subterrâneas [5-9]. Através da incorporação de esferas de poliestireno expandido em diferentes frações volumétricas no concreto, uma argamassa ou pasta cimentícia pode ser preparada resultando em ampla faixa de densidade do material. Os agregados de isopor podem substituir em parte ou completamente os agregados miúdos comumente usados no concreto ou a areia no caso de massas cimentícias. Muitos estudos foram feitos com a incorporação de poliestireno expandido em massas cimentícias, sendo a fase ligante o cimento Portland comum. Em alguns trabalhos, 
para compensar a característica hidrófoba do poliestireno, aditivos tais como resinas epóxi emulsificadas em água e dispersões de polivinilpropionato foram adicionadas [10]; ou esferas de isopor tratadas quimicamente para evitar a segregação nas misturas com o concreto [11]. Outros pesquisadores reportaram que as esferas de isopor tendem a flutuar, o que pode resultar em uma mistura não homogênea devido à segregação, fazendo o uso de aditivos necessários $[6,7]$. Além disso, as maiorias dos estudos foram feitos com concretos de densidades, $<1300 \mathrm{~kg} / \mathrm{m}^{3}$, com resistência $<12$ $\mathrm{MPa}$. A obtenção e as propriedades mecânicas de concreto com adição de esferas de isopor foram estudadas $[12,13]$. Para evitar os efeitos de segregação, foi estudada a adição de areia fina, $<2,3 \mathrm{~mm}$. Foram obtidos cimentos com densidade variando de 1500 a $2000 \mathrm{~kg} / \mathrm{m}^{3}$ com resistência entre 10 e $20 \mathrm{MPa}$, para adição de isopor na faixa de $20 \mathrm{a}$ $40 \%$ em volume. Tang et al. [14] adicionaram poliestireno expandido na faixa de 20 e $60 \%$ de volume, relatando que a densidade, a resistência mecânica e o módulo de elasticidade do compósito diminuem em função da concentração do poliestireno expandido da mistura. Além disso, as retrações em longo prazo dos compósitos são fortemente dependentes da fração volumétrica do poliestireno expandido e do tempo de cura.

Compósitos cimentícios com a adição de poliestireno expandido foram estudados em ampla faixa de densidades (550-2200 kg/m $\left.\mathrm{m}^{3}\right)$ e concentração de EPS entre $95 \%$ e $0 \%$ [15]. Os resultados foram comparados com os de outros compósitos, observando que o compósito cimentício com adição de EPS apresentou menor absorção de água do que o concreto normal, além de uma melhor resistência química. Os autores reportaram também que com o aumento da fração volumétrica de EPS há um aumento na permeabilidade e absorção de água dos compósitos cimentícios.

Neste trabalho foi estudada a influência da quantidade de areia fina em 5,10 e $20 \%$ e da quantidade de isopor em 20, 40 e $60 \%$ nas propriedades de compósitos de matriz cimentícia.

\section{MATERIAIS E MÉTODOS}

Neste experimento, a matriz do compósito foi o cimento Portland (CP-V) fornecido pela empresa Holcim S.A. do Brasil e areia fina passante na malha 80 mesh $(0,177 \mathrm{~mm})$, e a fase dispersa esferas de isopor de diâmetro $<5 \mathrm{~mm}$.

As variáveis investigadas neste experimento foram: densidade volumétrica, densidade relativa aparente, porosidade aparente, absorção de água, resistência à compressão e módulo de elasticidade. Dentre os fatores de maior relevância e possíveis de serem controlados, escolheram-se dois: fração em massa de areia, $(5 \%, 10 \%$ e $20 \%)$ e fração volumétrica de isopor $(20 \%, 40 \%$ e $60 \%)$. Os fatores mantidos constantes neste experimento foram: tempo de cura ( 28 dias), razão em massa água/cimento 0,4 ; tipo de matriz (cimento Portland) e temperatura ambiente de fabricação $\left(25^{\circ} \mathrm{C}\right)$. A Tabela I mostra os níveis e fatores experimentais investigados, estabelecendo um planejamento
Tabela I - Condições experimentais, planejamento fatorial completo $\left(3^{2}\right)$.

[Table I - Experimental conditions, complete factorial $\left.\operatorname{design}\left(3^{2}\right) \cdot\right]$

\begin{tabular}{ccc}
\hline $\begin{array}{c}\text { Condições } \\
\text { Experimentais }\end{array}$ & $\begin{array}{c}\text { Areia } \\
(\%)\end{array}$ & $\begin{array}{c}\text { Isopor } \\
\text { (\%) volume }\end{array}$ \\
\hline C1 & 5 & 20 \\
C2 & 5 & 40 \\
C3 & 5 & 60 \\
C4 & 10 & 20 \\
C5 & 10 & 40 \\
C6 & 10 & 60 \\
C7 & 20 & 20 \\
C8 & 20 & 40 \\
C9 & 20 & 60 \\
\hline
\end{tabular}

fatorial do tipo $3^{2}$, que fornece 9 condições experimentais distintas.

O método aleatório foi adotado na etapa de preparação dos corpos-de-prova, como também na etapa de realização dos ensaios. Isto permitiu uma ordenação arbitrária das condições experimentais, evitando que efeitos de fatores não-controláveis afetassem as variáveis-respostas [10].

Para a fabricação dos compósitos foram utilizados moldes cilíndricos de plástico com dimensões de $47,5 \mathrm{~mm}$ de diâmetro e 95,0 $\mathrm{mm}$ de altura, ou seja, altura igual a duas vezes o diâmetro. Misturadas as fases, o material foi vazado nos moldes e os corpos de prova, após cura, foram cortados para garantir o paralelismo para realização do ensaio de compressão. Seis corpos de prova foram preparados para cada condição experimental. Considerando a adoção de duas réplicas e nove condições experimentais, sendo assim foram preparados 108 corpos de prova. A réplica consiste na repetição da condição experimental, proporcionando a estimativa do erro experimental de uma resposta individual. A extensão desse erro é importante na decisão se existem ou não efeitos significativos que possam atribuir à ação dos fatores. O software estatístico Minitab versão 14 foi utilizado para o tratamento dos dados, utilizando a ferramenta Design of Experiment (DOE) e análise de variância (ANOVA).

Adensidade volumétrica, densidade aparente, porosidade e absorção de água foram medidas usando as seguintes relações (A) - (D):

$$
\begin{aligned}
& \mathrm{B}=\frac{\mathrm{M}_{1}}{\mathrm{~V}} \\
& \mathrm{~T}=\frac{\mathrm{M}_{1}}{\mathrm{M}_{1}-\mathrm{M}_{3}} \\
& \mathrm{P}=\frac{\mathrm{M}_{2}-\mathrm{M}_{1}}{\mathrm{M}_{2}-\mathrm{M}_{3}} \times 100
\end{aligned}
$$




$$
\mathrm{E}=\frac{\mathrm{M}_{2}-\mathrm{M}_{1}}{\mathrm{M}_{1}} \times 100
$$

sendo B a densidade volumétrica $\left(\mathrm{g} / \mathrm{cm}^{3}\right), \mathrm{M}_{1}$ a massa do compósito seco (g), $\mathrm{T}$ a densidade relativa aparente, $\mathrm{M}_{2}$ a massa saturada por imersão no vácuo $(\mathrm{g}), \mathrm{P}$ a porosidade aparente, $\mathrm{M}_{3}$ a massa saturada suspensa abaixo da água (g), E a absorção de água, e V o volume do corpo de prova $\left(\mathrm{cm}^{3}\right)$.

$\mathrm{O}$ ensaio de porosidade e densidade aparente seguiu recomendações da norma britânica BS EN ISO 105453 (1995) [16]. Para investigar os valores da resistência à compressão, foi utilizada a máquina universal de ensaios, sendo os testes de compressão feitos com uma velocidade de $5 \mathrm{~mm} / \mathrm{min}$.

O módulo de elasticidade dinâmico foi medido por meio dos valores da dimensão, massa e frequência de ressonância de cada corpo de prova. Para medir a frequência de ressonância, foi feito ensaio não destrutivo usando o Erudite MKIV Resonant Frequency Test System. Esse estudo foi feito segundo a norma ASTM - C215 - 08 [17] para frequência fundamental longitudinal. $\mathrm{O}$ módulo da elasticidade dinâmico foi calculado pela equação $\mathrm{E}$ :

$$
\mathrm{E}=5,093 \times\left(\frac{\mathrm{L}}{\mathrm{d}^{2}}\right) \times \mathrm{M} \times\left(\mathrm{n}^{\prime}\right)^{2}
$$

sendo $E$ o módulo de elasticidade dinâmico, $L$ o comprimento do corpo de prova, $d$ o diâmetro, $M$ a massa e $n$ ' a frequência fundamental longitudinal.

\section{RESULTADOS}

A Fig. 1 mostra uma foto de um corpo de prova contendo $40 \%$ de esferas de isopor como agregado. Observa-se a formação de poros internos que podem ser atribuídos ao processo de fabricação. A Fig. 2 apresenta uma imagem do corte longitudinal dos corpos de prova investigados (C1C9), podendo verificar uma distribuição das partículas de isopor homogênea em todas as condições experimentais.

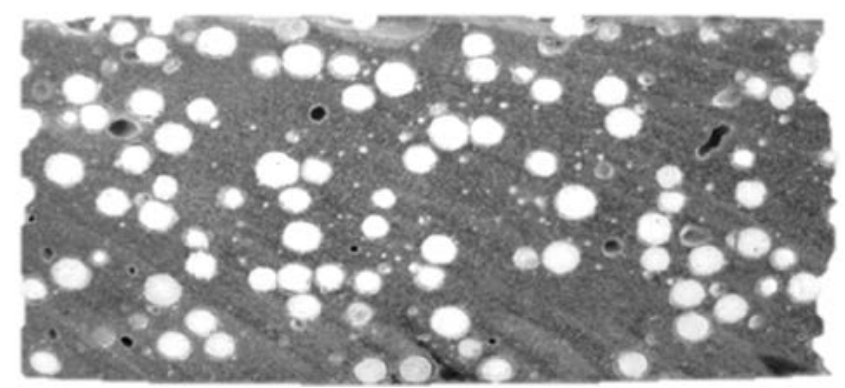

Figura 1: Corte longitudinal de um corpo de prova contendo $20 \%$ de isopor e $20 \%$ de areia (composição C7), após 28 dias de cura. [Figure 1: Longitudinal section of a specimen containing 20\% of styrofoam and $20 \%$ sand (composition C7) after 28 days of curing.]

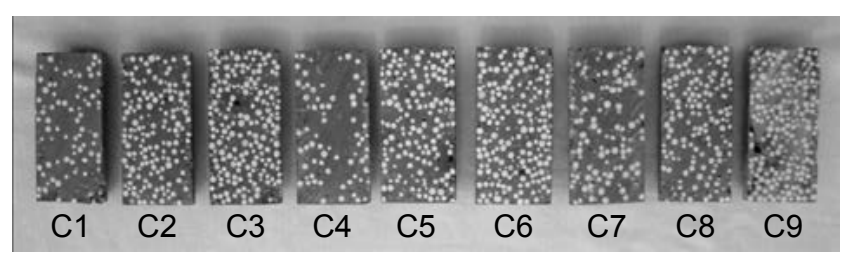

Figura 2: Corte longitudinal dos corpos de prova de todas as condições experimentais.

[Figure 2: Longitudinal section of the specimens of all experimental conditions.]

A Tabela II apresenta os resultados da análise de variância (ANOVA) para as médias das variáveis respostas investigadas. Os fatores relacionados a $\mathrm{P}$-valor menor ou igual a 0,05 ( $95 \%$ de confiabilidade) são considerados significativos. O efeito principal de um fator deve ser interpretado individualmente apenas se não há evidência de que o fator não interage com outros fatores. Quando um ou mais efeitos de interação de ordem superior são significativos, os fatores que interagem devem ser considerados conjuntamente [18]. Os P-valores, sublinhados na Tabela II, correspondem aos fatores significativos analisados neste trabalho. $\mathrm{O}$ valor de $\mathrm{R}^{2}$ adjunto exibido na ANOVA mede a proporção da variabilidade preditora presente na equação de

Tabela II - Análise de variância (ANOVA).

\begin{tabular}{|c|c|c|c|c|c|c|}
\hline \multicolumn{2}{|r|}{ ANOVA } & \multicolumn{5}{|c|}{$P-$ VALOR $\leq 0,05$} \\
\hline \multirow{3}{*}{ 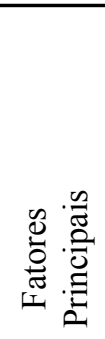 } & $\begin{array}{c}\text { Fatores } \\
\text { Experimentais }\end{array}$ & $\begin{array}{l}\text { Densidade } \\
\text { Volumétrica } \\
\left(\mathrm{g} / \mathrm{cm}^{3}\right)\end{array}$ & $\begin{array}{c}\text { Densidade } \\
\text { Aparente }\end{array}$ & $\begin{array}{l}\text { Porosidade } \\
\text { Aparente }\end{array}$ & $\begin{array}{l}\text { Resistência à } \\
\text { Compressão } \\
\text { (MPa) }\end{array}$ & $\begin{array}{c}\text { Módulo de } \\
\text { Elasticidade } \\
\text { Dinâmico } \\
(\mathrm{GPa})\end{array}$ \\
\hline & Fração de Areia & 0,476 & $\underline{0,021}$ & $\underline{0,014}$ & 0,049 & $\underline{0,007}$ \\
\hline & Fração de Isopor & $\underline{0,000}$ & $\underline{0,000}$ & $\underline{0,000}$ & 0,000 & $\underline{0,000}$ \\
\hline \multirow[t]{2}{*}{ 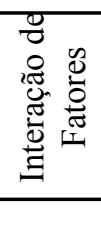 } & $\begin{array}{l}\text { Fração de Areia * } \\
\text { Fração de Isopor }\end{array}$ & 0,253 & 0,304 & 0,085 & $\underline{0,028}$ & 0,080 \\
\hline & $\mathrm{R}^{2}$ (Adjunto) & $99,05 \%$ & $99,16 \%$ & $90,32 \%$ & $98,79 \%$ & $99,04 \%$ \\
\hline
\end{tabular}

[Table II - Analysis of variance (ANOVA).] 
regressão. Quanto mais próximo de 1 (ou de 100\%) melhor a qualidade da equação ajustada aos dados.

Os valores da densidade volumétrica dos compósitos variaram de 1210 a $1640 \mathrm{~kg} / \mathrm{m}^{3}$. O P-valor $(0,00)$ sublinhado na Tabela II indica que o efeito da fração de isopor é significativo. Já o P-valor para fração de areia $(0,476)$ é maior que 0,05 , evidenciando que este fator não influencia diretamente a densidade volumétrica. $\mathrm{O}$ valor de $\mathrm{R}^{2}$ ajustado foi de $99,05 \%$ indicando que a qualidade de ajuste do modelo foi satisfatória. A Fig. 1 mostra o gráfico de efeito do fator principal fração de isopor para a variável resposta densidade volumétrica. Pode ser observado na Fig. 3 que a fração de isopor afeta diretamente no valor médio da densidade volumétrica com uma variação percentual média de até $32,7 \%$, ou seja, quanto maior a fração de isopor menor é a densidade, devido à baixa densidade do isopor $\left(25 \mathrm{~kg} / \mathrm{m}^{3}\right)$ usado nos compósitos.

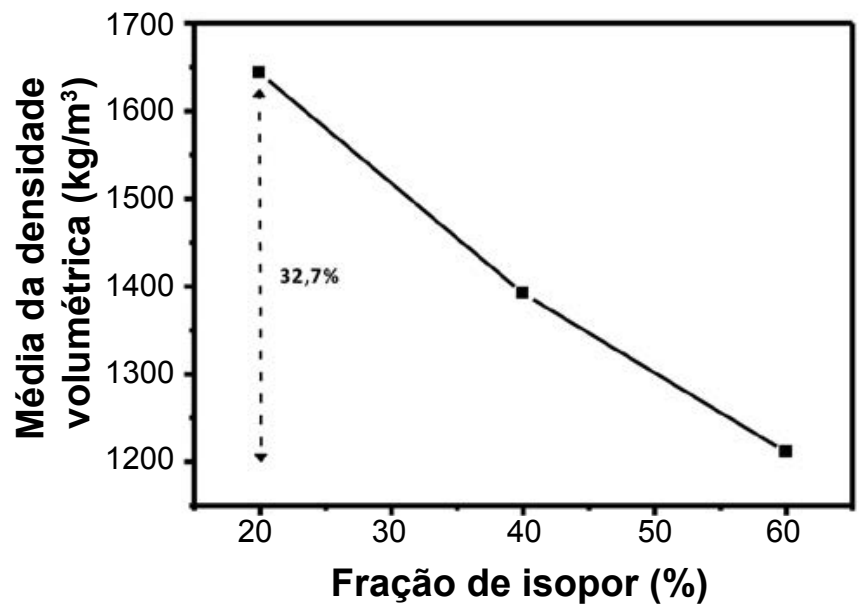

Figura 3: Efeito da fração de isopor na média da densidade volumétrica dos compósitos.

[Figure 3: Effect of polystyrene fraction on the average bulk density of the composites.]

Os valores da densidade aparente variaram entre 1290 e $1800 \mathrm{~kg} / \mathrm{m}^{3}$, correspondendo a uma pequena variação percentual média de $3,3 \%$. Os fatores principais, fração de areia $(0,021)$ e fração de isopor $(0,000)$, são considerados significativos, exibindo P-valor inferior a 0,05 . O valor de $\mathrm{R}^{2}$ ajustado de $99,16 \%$ indica o ajuste satisfatório do modelo adotado aos resultados da densidade aparente. A Fig. 4 mostra o gráfico de efeito do fator principal fração de areia para a variável resposta densidade aparente. Este comportamento já era esperado, visto que, a densidade aparente das partículas de areia é superior aos demais constituintes, promovendo o aumento da densidade dos compósitos.

A Fig. 5 mostra o gráfico de efeito do fator principal fração de isopor para a variável resposta densidade aparente. $\mathrm{O}$ isopor contribui para a diminuição da densidade aparente, visto que sua densidade aparente é muito baixa. A variação percentual média de $36 \%$ é observada entre os níveis de 20 e $60 \%$ de adições de isopor.

Os valores da porosidade aparente variaram de 8,93 a $11,68 \%$. Os P-valores para os fatores principais, fração de

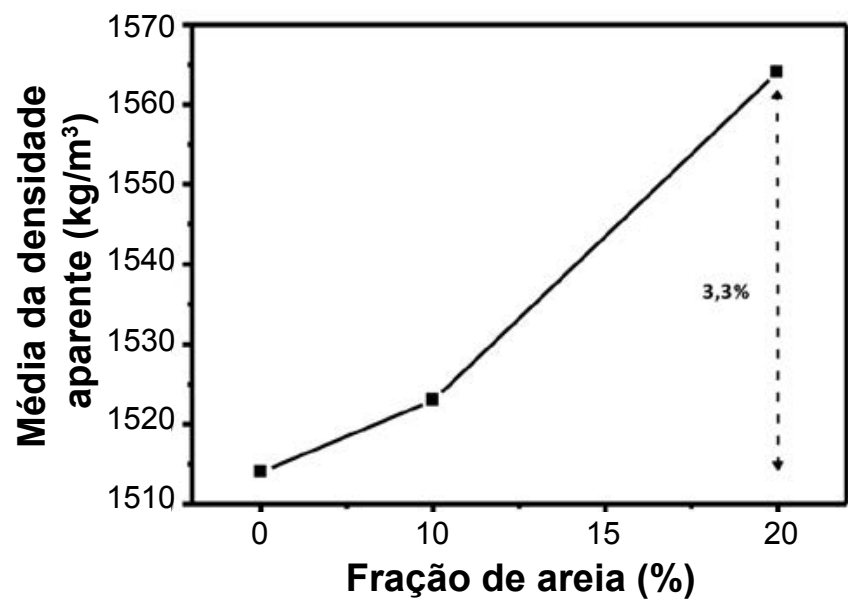

Figura 4: Efeito da fração de areia na média da densidade aparente dos compósitos.

[Figure 4: Effect of sand fraction on the average bulk density of the composites.]

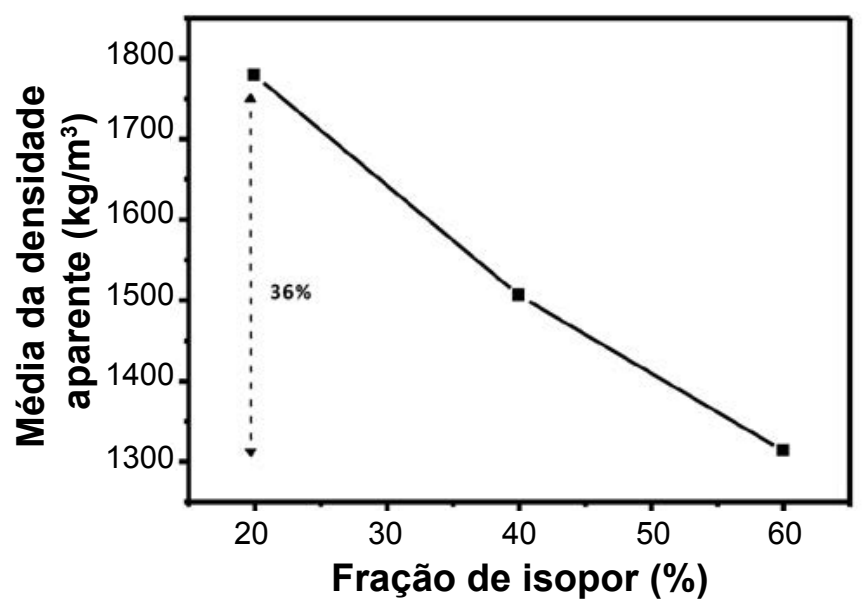

Figura 5: Efeito da fração de isopor na média da densidade aparente dos compósitos.

[Figure 5: Effect of polystyrene fraction on the average bulk density of the composites.]

areia $(0,014)$ e fração de isopor $(0,000)$, mostram que cada um deles afeta diretamente na variável resposta. $\mathrm{O}$ valor de $\mathrm{R}^{2}$ ajustado de $90,32 \%$ indica o ajuste satisfatório do modelo adotado aos resultados da Porosidade Aparente obtidos.

A Fig. 6 mostra o gráfico de efeito do fator principal fração de areia para a variável resposta porosidade aparente. É possível observar que a adição de partículas de areia promove a redução da porosidade no compósito quando é adicionada a fração de $10 \% \mathrm{em}$ massa. Este comportamento pode ser atribuído ao melhor fator de empacotamento exibido neste percentual de areia de $10 \%$, por outro lado, observa-se um aumento da porosidade para as frações de areia de 5 e $20 \%$, chegando a $9 \%$ na variação percentual. O estudo do empacotamento de partículas não foi o foco desta pesquisa, tornando este o tema para futuras investigações.

AFig. 7 mostra o gráfico de efeito do fator principal fração de isopor para a variável resposta porosidade aparente. Pode ser observada uma variação percentual média de $18,8 \%$ entre as frações de 20 e $60 \%$ isopor. O aumento do percentual 


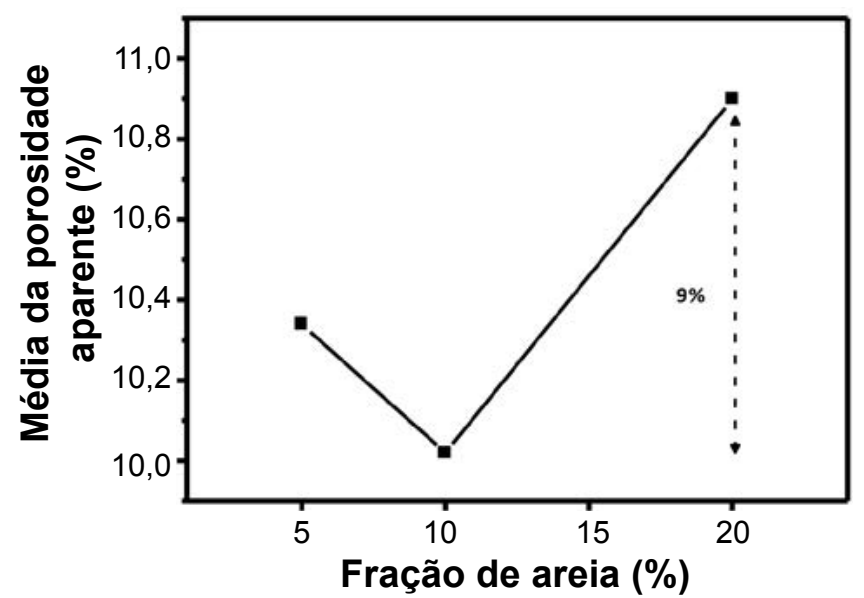

Figura 6: Efeito da fração de areia na média da porosidade aparente dos compósitos.

[Figure 6: Effect of sand fraction on the average porosity of the composites.]

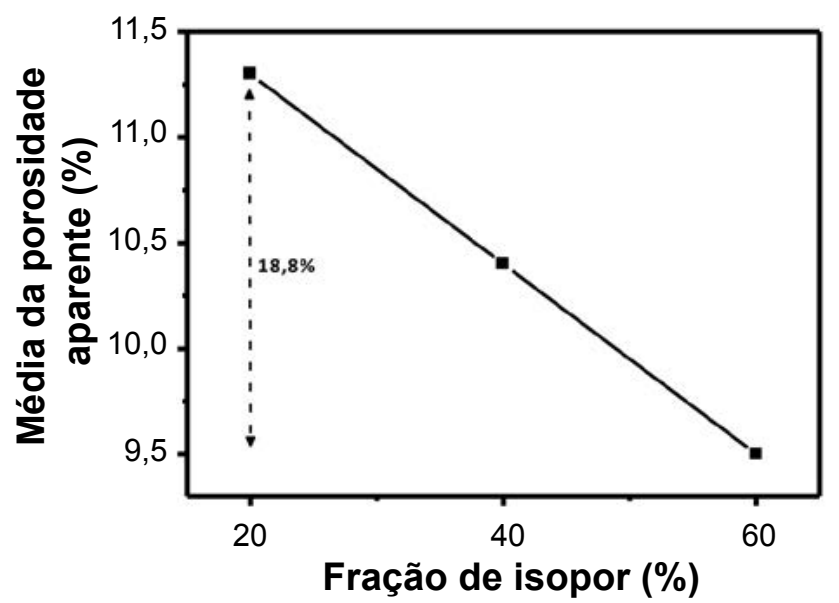

Figura 7: Efeito da fração de isopor na média da porosidade aparente dos compósitos.

[Figure 7: Effect of polystyrene fraction on the average porosity of the composites.]

de partículas de isopor implica na redução de volume da matriz cimentícia, sendo esta a principal responsável pela porosidade aparente do material.

Os valores de resistência à compressão dos compósitos variaram de 7,37 a 18,71 MPa. A interação de segunda ordem "fração de areia e fração de isopor" foi significativa, exibindo um P-valor de 0,028 (ver Tabela II). O valor de $\mathrm{R}^{2}$ ajustado de $98,79 \%$ indica que o modelo se ajustou adequadamente aos resultados obtidos de resistência à compressão. A Fig. 8 exibe o efeito da interação dos fatores "fração de areia e fração de isopor" sobre a resistência à compressão. Pode ser observado que apesar da interação dos dois fatores serem significativa a fração de isopor provoca uma maior variação na resistência à compressão, revelando uma diferença percentual de aproximadamente $121 \%$ entre as frações de 20 e $60 \%$, visto que suas propriedades mecânicas são ínfimas se comparadas às propriedades do cimento. Nota-se que o efeito da adição de areia sobre a resistência varia para cada nível de isopor

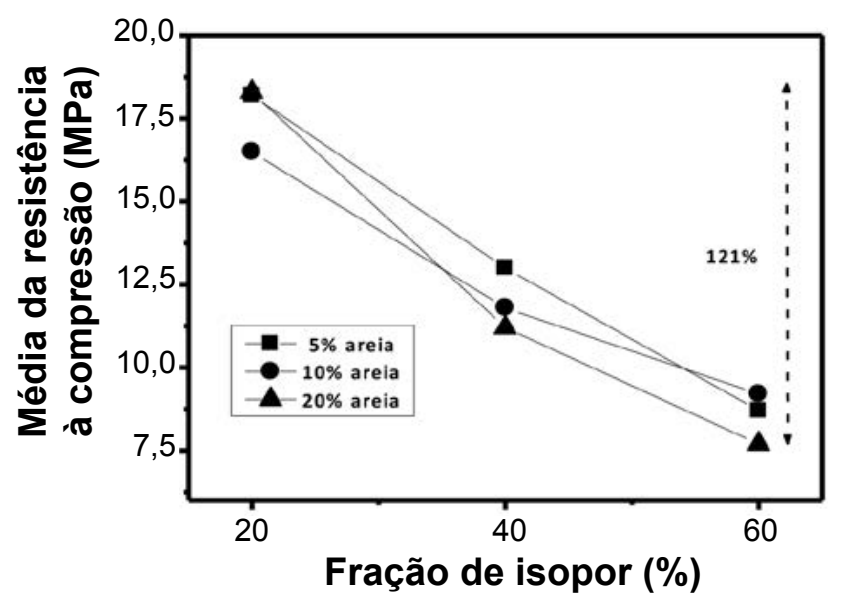

Figura 8: Efeito da interação fração de areia e fração de isopor na média da resistência à compressão.

[Figure 8: Interaction effect of sand fraction and fraction of styrofoam on the average compressive strength.]

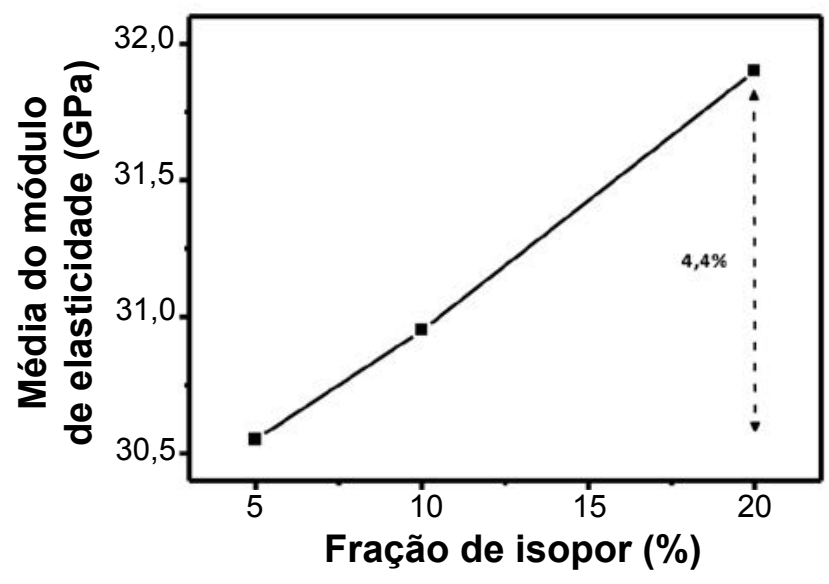

Figura 9: Efeito da fração de areia na média do módulo de elasticidade dinâmico dos compósitos.

[Figure 9: Effect of fraction of sand on the average dynamic modulus of elasticity of composite.]

adicionado, podendo ser atribuído ao fator de empacotamento das partículas.

Os valores do módulo de elasticidade dinâmico variaram entre 26,06 a $37,31 \mathrm{GPa}$. Os P-valores para os fatores principais, fração de areia $(0,007)$ e fração de isopor $(0,000)$, mostram que cada um deles afeta diretamente na variável resposta. O valor de $\mathrm{R}^{2}$ ajustado de $99,04 \%$ indica o ajuste satisfatório do modelo adotado aos resultados de módulo de elasticidade dinâmico. A Fig. 9 mostra o gráfico de efeito do fator principal fração de areia para a variável resposta módulo de elasticidade dinâmica. A adição das partículas de areia promove o aumento $(4,4 \%)$ do módulo de elasticidade, o que pode ser atribuído a maior rigidez das partículas de areia (sílica).

A Fig. 10 mostra o gráfico de efeito do fator principal fração de isopor para a variável resposta módulo de elasticidade dinâmico. À medida que a fração volumétrica do isopor aumenta, observa-se uma redução percentual 
de $35 \%$ no valor do módulo de elasticidade dinâmico devido ao baixíssimo módulo de elasticidade do isopor. É importante ressaltar que o método de medir o módulo de elasticidade por frequência de ressonância foi capaz de detectar o tipo de agregado e suas frações, principalmente para as partículas de isopor que exibem uma densidade muito baixa, mostrando-se uma técnica adequada para caracterização dos compósitos investigados.

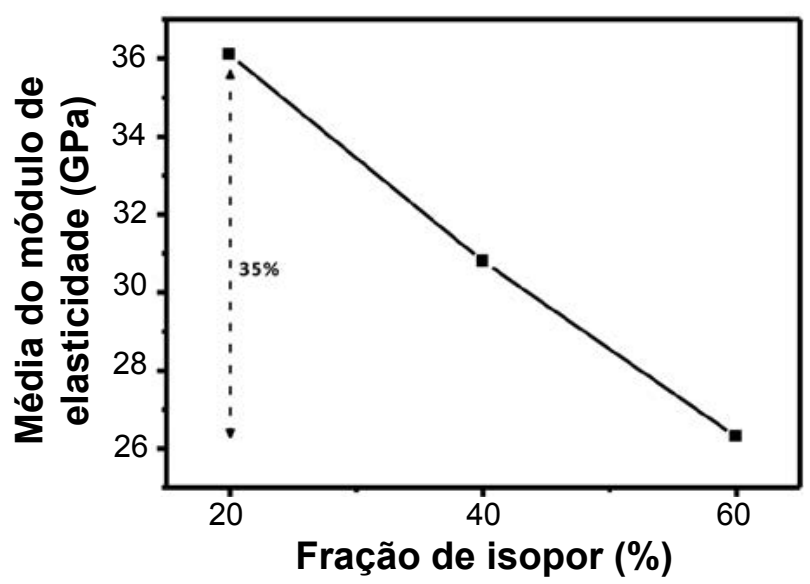

Figura 10: Efeito da fração de isopor na média do módulo de elasticidade dinâmico dos compósitos.

[Figure 10: Effect of fraction of styrofoam on the average dynamic modulus of elasticity of composite.]

\section{CONCLUSÕES}

Dos resultados obtidos nesse trabalho, pode-se concluir que a quantidade de areia adicionada influenciou pouco nas propriedades dos compósitos preparados, mesmo nos casos onde se observou uma interação significativa nos resultados de densidade aparente, porosidade aparente e módulo de elasticidade. As variações observadas nessas propriedades ficaram abaixo de $10 \%$. Já a quantidade de isopor adicionada afetou significativamente todas propriedades estudadas dos compósitos preparados, alcançando a uma variação de $121 \%$ no valor médio da resistência à compressão. O compósito da menor densidade $\left(1210 \mathrm{~kg} / \mathrm{m}^{3}\right)$ foi preparado com $60 \%$ de isopor e obteve uma resistência à compressão de $8,38 \mathrm{MPa}$. O método da frequência de ressonância mostrou-se adequado na caracterização de compósitos cimentícios com partículas de isopor, sendo capaz de detectar não somente o tipo de agregado, como também os percentuais adicionados. Conclui-se também que a incorporação de isopor em maiores quantidades possa diminuir a densidade ainda mais, mantendo uma resistência suficiente para aplicações não estruturais, tais como revestimento de painel, muro cortina e piso.

\section{AGRADECIMENTOS}

À FAPEMIG pelo apoio financeiro recebido.

\section{REFERÊNCIAS}

[1] A. Short, W. Kinniburgh, "Lightweight Concrete", $3^{\text {rd }}$ Ed., Ing.: Appl. Sci. Publishers (1978).

[2] V. Sussman, Lightweight plastic aggregate concrete, J. ACI (1975) 321-323.

[3] D. J. Cook in: R. N. Swamy (Ed.), "Expanded Polystyrene Concrete, Concrete Technology and Design": (1) New Concrete Materials, Surrey Univ. Press, London, UK (1983) 41-69.

[4] A. Godwin, Versatile concrete blocks for the third world, J. Indian Concr. (1982) 240-241.

[5] A. N. Hanna, Properties of expanded polystyrene concrete and applications for pavement sub-bases, Res. Develop. Bull. Portland Cem. Assoc. (Rd 055.01P).

[6] C. Bagon, S. Frondistou-Yannas, Marine floating concrete made with polystyrene expanded beads, Mag. Concr. Res. 28 (1976) 225-229.

[7] S. H. Perry, P. H. Bischaff, K. Yamura, Mix details and material behavior of polystyrene aggregate concrete, Mag. Concr. Res. 43 (1991) 71-76.

[8] G. C. Hoff, "New applications for low density concretes, Lightweight Concrete", ACI SP, vol. 29, Am. Concr. Institute, Detroit (1971) 181-220.

[9] P. H. Bischoff, K. Yamura, S. H. Perry,"Polystyrene aggregate concrete subjected to hard impact", Proc. of the Institution of Civil Eng., Part 2, London 89 (1989) 225-239.

[10] D. J. Cook, Expanded polystyrene beads as lightweight aggregate for concrete, Precast Concr. 4 (1973) 691-693.

[11] R. S. Ravindrarajah, A. J. Tuck, Properties of hardened concrete containing treated expanded polystyrene beads, Cem. Concr. Compos. 16 (1994), 273-277.

[12] K. Babu, D. S. Babu, Behaviour of lightweight expanded polystyrene concrete containing silica fume, Cem. Concr. Res. 33 (2003) 755-762.

[13] M. H. Zhang, O. E. Gjorv, Mechanical properties of high strength lightweight concrete, ACI Mater. J. 88 (3) (1991), 240- 247.

[14] W. C. Tang, Y. Lo, A. Nadeem, Mechanical and drying shrinkage properties of structural graded polystyrene aggregate concrete, Cem. Concr. Composites 30 (2008) 403 409.

[15] K. Babu, D. S. Babu, Performance of fly ash concretes containing lightweight EPS aggregates, Cem. Concr. Composites 26 (2004) 605-611.

[16] Norma BS EN ISO 10545-3: Determination of water absorption, apparent porosity, apparent relative density and bulk density (1997).

[17] Norma ASTM-C215-08: Standard Test Method for Fundamental Transverse, Longitudinal, and Torsional Frequencies, Concr. Specimens (2008).

[18] M. C. Werkema, S. Aguiar, "Planejamento e análise de experimentos: como identificar e avaliar as principais variáveis influentes em um processo", Belo Horizonte: Fundação Christiano Ottoni, Escola de Engenharia da UFMG (1996).

(Rec. 13/05/2013, Rev. 05/06/2013, Ac. 15/12/2013 